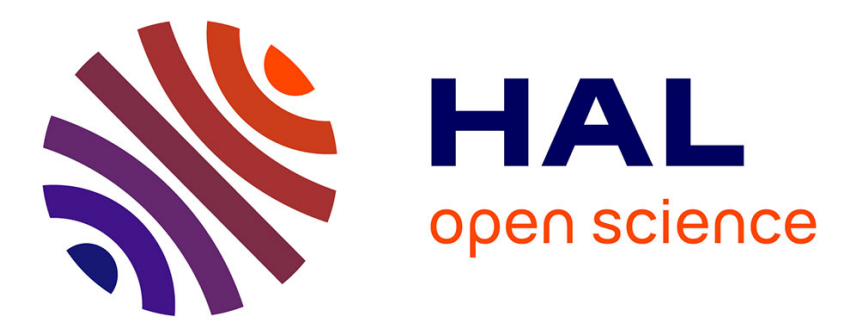

\title{
Sound propagation in amorphous metallic Ni-P
}

\author{
G. Bellessa, M. Cagnon, J.F. Sadoc, P. Doussineau, A. Levelut
}

\section{To cite this version:}

G. Bellessa, M. Cagnon, J.F. Sadoc, P. Doussineau, A. Levelut. Sound propagation in amorphous metallic Ni-P. Journal de Physique Lettres, 1976, 37 (11), pp.291-293. 10.1051/jphyslet:019760037011029100 . jpa-00231295

\section{HAL Id: jpa-00231295 https://hal.science/jpa-00231295}

Submitted on 1 Jan 1976

HAL is a multi-disciplinary open access archive for the deposit and dissemination of scientific research documents, whether they are published or not. The documents may come from teaching and research institutions in France or abroad, or from public or private research centers.
L'archive ouverte pluridisciplinaire HAL, est destinée au dépôt et à la diffusion de documents scientifiques de niveau recherche, publiés ou non, émanant des établissements d'enseignement et de recherche français ou étrangers, des laboratoires publics ou privés. 


\author{
Classification \\ Physics Abstracts \\ $7.260-8.275-9.150$
}

\title{
SOUND PROPAGATION IN AMORPHOUS METALLIC Ni-P
}

\author{
G. BELLESSA, M. CAGNON and J. F. SADOC
}

Laboratoire de Physique des Solides (*), Université Paris-Sud, 91405 Orsay, France

and

\section{P. DOUSSINEAU and A. LEVELUT}

Laboratoire d'Ultrasons $\left({ }^{*}\right)$, Université Pierre-et-Marie-Curie, Tour 13, 4, place Jussieu, 75230 Paris Cedex 05, France

(Reçu le 7 juillet 1976, accepté le 23 juillet 1976)

\begin{abstract}
Résumé. - Des mesures d'atténuation et de vitesse acoustiques à basses températures dans Ni-P sont rapportées. L'atténuation a été mesurée à $9 \mathrm{GHz}$ entre 1,5 et $4 \mathrm{~K}$. La vitesse a été mesurée à $75 \mathrm{MHz}$ entre 0,5 et $20 \mathrm{~K}$. Aucune preuve de l'existence de systèmes à deux niveaux n'a été obtenue.

Abstract. - Sound attenuation and velocity measurements at low temperatures in Ni-P are reported. The attenuation is measured at $9 \mathrm{GHz}$ between 1.5 and $4 \mathrm{~K}$. The velocity is measured at $75 \mathrm{MHz}$ between 0.5 and $20 \mathrm{~K}$. No evidence of the existence of two-level systems is obtained.
\end{abstract}

1. Introduction. - Amorphous insulators have unusual thermal properties at low temperatures : large specific heat proportional to the temperature $T$ and a low thermal conductivity varying as $T^{2}$. Furthermore the attenuation and the velocity of acoustic waves behave in peculiar way at low temperatures [1]. The attenuation is strongly dependent on the acoustic amplitude and the velocity decreases as $\log T$ in a low temperature range [2]. The acoustic behaviour is well described with the model, proposed by Anderson et al. [3] and Phillips [4], which assumes the existence of two-level systems. In amorphous metal, to our knowledge, no acoustic experiment has been performed to look for similar properties. However Cochrane et al. [5] have studied the electrical resistivity of amorphous metallic Ni-P. They have observed a logarithmic anomaly in the temperature-dependent resistivity below $15 \mathrm{~K}$ and they have suggested that this anomaly could be explained through the existence of two-level systems in such materials. In this letter we report sound velocity measurements down to $0.5 \mathrm{~K}$ and attenuation measurements at $9 \mathrm{GHz}$ in metallic $\mathrm{Ni}-\mathrm{P}$ in amorphous phase.

2. Samples. - Amorphous platelets of Ni-P alloys with concentration near the eutectic composition (19 atoms \%) were prepared by electrodeposition from

$\left(^{*}\right)$ Associated with the Centre National de la Recherche Scientifique. a bath, similar to those described by Brenner et al. [6]. The platelets were about $1 \mathrm{~mm}$ thick. Their amorphous structure was checked by X-ray diffraction. This structure can be described by tetrahedric close packing, with local icosaedric order [7]. The Ni-P amorphous phase is stable up to $520 \mathrm{~K}$.

3. Sound velocity measurements. - The velocity variation of Rayleigh waves has been measured as a function of temperature. Rayleigh waves rather than acoustic bulk waves have been used because the samples are thin platelets and it is easier to obtain a large acoustic path with Rayleigh waves (about $1 \mathrm{~cm}$ ) than with acoustic bulk waves. Thus the velocity variation was measured with a precision better than $3 \times 10^{-5}$. The experimental procedure to generate Rayleigh waves on metal has already been described [8]. Two piezoelectric $\mathrm{ZnS}$ films are evaporated on the sample surface. These films are $5 \mathrm{~mm}$ distant from each other and support two evaporated metallic combs. Rayleigh waves are generated with one comb and detected with the second one using a pulse technique. Amorphous Ni-P is an isotropic media. Hence, a Rayleigh wave is an elliptic polarized wave, the velocity of which is about $0.9 v_{\mathrm{T}}$ (where $v_{\mathrm{T}}$ is the transverse sound wave velocity). In Ni-P, the Rayleigh wave velocity is $v_{\mathrm{R}}=2.37 \times 10^{5} \mathrm{~cm} / \mathrm{s}$. Figure 1 shows the relative variation of the velocity as a function of temperature between 0.5 and $20 \mathrm{~K}$. The velocity is well constant between 0.5 and $3.5 \mathrm{~K}$. Then it decreases linearly when the temperature is increased 
up to $20 \mathrm{~K}$. A noticeable property of this curve is the very good definition of the temperature at which the velocity begins to change $(3.5 \mathrm{~K})$. Such an anomaly does not appear in the velocity variation as a function of temperature in crystals.

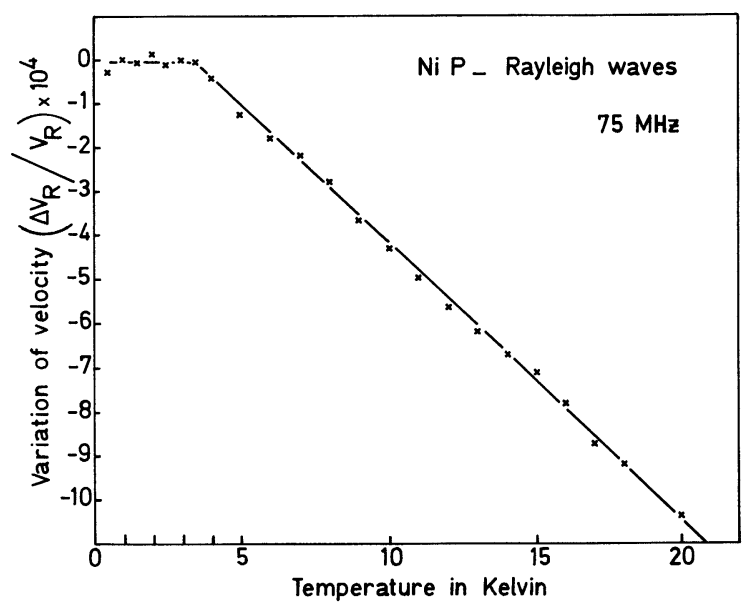

FIG. 1. - Relative variation of the Rayleigh wave velocity as a function of temperature in amorphous Ni-P. The velocity is $2.37 \times 10^{5} \mathrm{~cm} / \mathrm{s}$. The accuracy of the relative measurements is better than $3 \times 10^{-5}$.

4. Sound attenuation measurements. - The attenuation measurements were performed at $9 \mathrm{GHz}$ with longitudinal bulk waves $\left(v_{\mathrm{L}}=5.0 \times 10^{5} \mathrm{~cm} / \mathrm{s}\right)$ generated with $\mathrm{X}$-cut quartz. Two types of measurements were made. Firsty, in order to detect any saturation effect, the attenuation as a function of the ultrasonic flux was measured at a given temperature $(1.4 \mathrm{~K})$. The results are reported in figure 2 ;

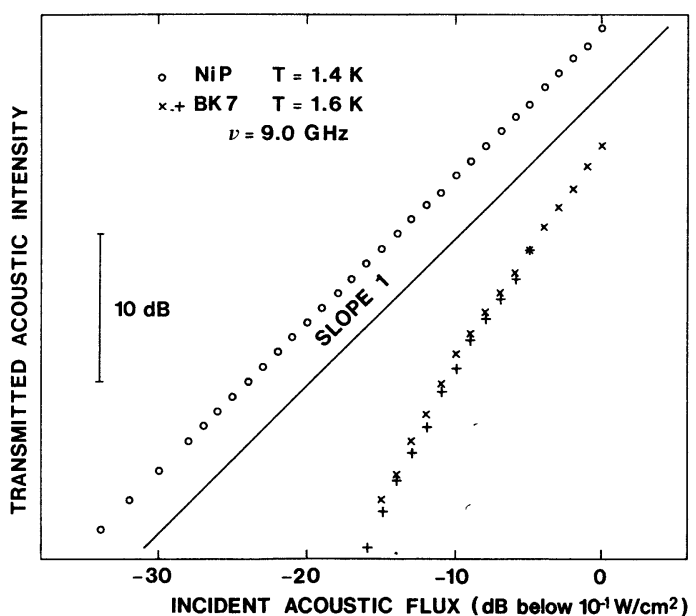

FIG. 2. - Intensity of the transmitted acoustic echo through a Ni-P sample and a borosilicate sample versus the incident acoustic flux. The experimental conditions were : $v=9.0 \mathrm{GHz}$; Ni-P length $0.77 \mathrm{~mm}$; BK 7 length $6.66 \mathrm{~mm}$. The relative vertical positions of the two curves are arbitrary. The absolute acoustic flux is known only within a factor of five.

for comparison, the results of the same measurements are shown for an amorphous insulator. No non-linear effect can be seen in the metal. Second, the attenuation variation as a function of the temperature has been measured between $: .5$ and $4.2 \mathrm{~K}$ at high ultrasonic flux, in Ni-P and in an amorphous insulator. In figure 3 , the non-resonant attenuation is clearly apparent in the insulator and not perceptible in Ni-P.

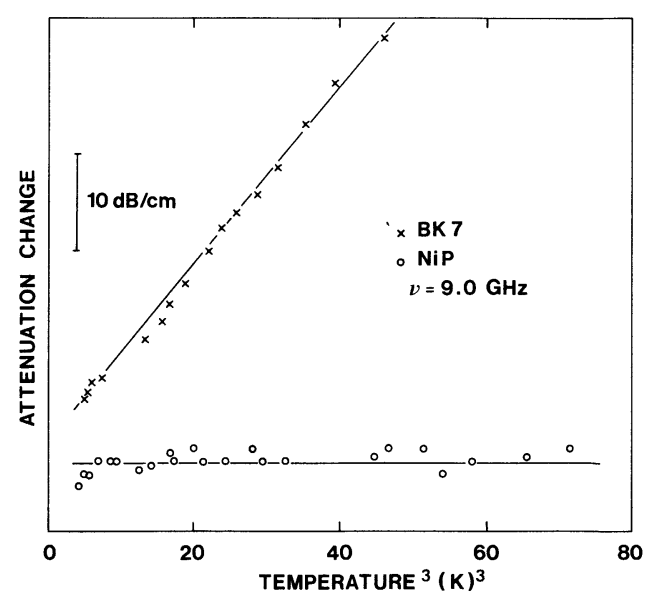

Fig. 3. - Attenuation change versus the cube of the temperature in a Ni-P sample and in a borosilicate sample. The experimental conditions were : $v=9.0 \mathrm{GHz}$; Ni-P length $2.33 \mathrm{~mm}$. BK 7 length $6.66 \mathrm{~mm}$; acoustic flux of the order of $0.1 \mathrm{~W} / \mathrm{cm}^{2}$. The relative vertical positions of the two curves are arbitrary.

5. Discussion. - According to the model of Anderson et al. and Phillips, a glass contains a distribution of two-level defects (often represented by fictitious spins $S=\frac{1}{2}$ ) with an energy spectrum smoothly varying from zero to a cut-off of about $0.1 \mathrm{eV}$. This model leads to some very peculiar properties of the acoustic propagation :

1) The resonant ultrasonic attenuation $l^{-1}$ is given by [9]

$$
l^{-1}=l_{\mathrm{ns}}^{-1}\left[1+K^{2} A^{2} T_{1} T_{2}\right]^{-1 / 2}
$$

where $A$ is the ultrasonic amplitude and $K$ is proportional to the coupling constant $G_{x}$ between the twolevel systems and the ultrasonic wave. Equation (1) shows that the attenuation is amplitude dependent through the term in brackets. $l_{\mathrm{ns}}^{-1}$ is the attenuation as the saturation is negligible (very low acoustic flux). It is proportional to the dimensionless coupling constant $C=n_{0} G_{x}^{2} / 4 \rho v^{2}$ where $n_{0}$ is the two-level system density of states and $v$ is the sound velocity.

2) Associated with the resonant attenuation, there is a variation of the sound velocity given by [2] :

$$
\frac{v(T)-v\left(T_{0}\right)}{v\left(T_{0}\right)}=C \ln \left(\frac{T}{T_{0}}\right) \text {. }
$$

This involves a very particular behaviour of the velocity which increases with increasing temperature. Equation (2) is valid up to about $2 \mathrm{~K}$ for an ultrasonic frequency of $100 \mathrm{MHz}$ [2].

3) At high acoustic flux, as the resonant attenuation is saturated, the dominant process becomes a relaxational process. This non-resonant process leads to an attenuation varying as $T^{3}$ up to about $5 \mathrm{~K}$ [10]. 
Thermal as well as acoustic properties are nearly identical for all the amorphous insulators. Therefore the numerical values of the fundamental parameters such as $n_{0}$ and $C$ are nearly the same for all these materials.

All the previous predictions must be compared with our experimental results.

The attenuation measurements show no evidence of a saturation effect. This means that $l_{\text {ns }}^{-1}$ is smaller than our experimental accuracy (here $5 \mathrm{~dB} / \mathrm{cm}$ in our sample which is $0.77 \mathrm{~mm}$ thick). In the same experimental conditions, an insulator would give $l_{\mathrm{ns}}^{-1} \simeq 50 \mathrm{~dB} / \mathrm{cm}$. The partial desaturation appearing in figure 2 is consistent with that value. These results mean that, if the two-level systems exist in Ni-P, then the coupling constant $C$ is one order of magnitude smaller than in a glass.

The velocity measurements show no decrease of the velocity as the temperature is decreasing down to $0.5 \mathrm{~K}$. Between 0.5 and $2 \mathrm{~K}$, the sound velocity is constant with an accuracy better than $3 \times 10^{-5}$. In the same temperature range, the relative velocity variation for a glass is typically $4 \times 10^{-4}[2]$ and very well follows equation (2). Here álso, the coupling constant $C$ with some hypothetical two-level systems would be at least one order of magnitude smaller than in glass.

The attenuation in Ni-P which has been shown above to be power-independent, is also temperature independent between 1.5 and $4.2 \mathrm{~K}$ within the experimental accuracy. Hence, there is no evidence of a relaxational attenuation by two-level systems. Here again, the comparison with the glass shows that the relevant coupling constant in $\mathrm{Ni}-\mathrm{P}$ would be one order of magnitude smaller.

6. Conclusion. - The aim of our experiments in Ni-P was to reveal the existence of two-level systems in metallic amorphous materials. However, we have observed none of the specific acoustical properties of the amorphous insulator : saturation of the attenuation, $T^{3}$-dependent attenuation and decrease of the sound velocity with decreasing temperature. These results are not consistent with the interpretation given by Cochrane et al. [5] of their resistivity experiment.

The sound velocity variation with temperature is quite different from that usually observed in crystals. However this behaviour cannot be presently connected with the general properties of amorphous materials.

\section{References}

[1] Arnold, W., Hunklinger, S., Stein, S. and Dransfeld, K., J. Non Cryst. Solids 14 (1974) 192.

[2] Piché, L., Maynard, R., Hunklinger, S. and JäCKLe, J. Phys. Rev. Lett. 32 (1974) 1426.

[3] Anderson, P. W., Halperin, B. and Varma, C., Phil. Mag. 25 (1972) 1.

[4] Phillips, W. A., J. Low Temp. Phys. 7 (1972) 351.

[5] Cochrane, R. W., Harris, R., Ström-Olson, J. O. and Zuckermann, M. J., Phys. Rev. Lett. 35 (1975) 676.
[6] Brenner, A., Couch, D. E. and Williams, E. K., J. Res. Nat. Bur. Stand. 44 (1950) 109.

[7] Dixmier, J., Bletry, J. and Sadoc, J. F., J. Physique Colloq. 36 (1975) C2-73.

[8] Bellessa, G., J. Physique Lett. 36 (1975) L-137.

[9] Jofrrin, J. and Levelut, A., J. Physique 36 (1975) 811.

[10] Jäckle, J., Piché, L., Arnold, W. and Hunklinger, S., J. Non Cryst. Solids 20 (1976) 365 